\title{
Product-Resolved Photodissociations of Iodotoluene Radical Cations ${ }^{\mathrm{s}}$
}

\author{
Seung Koo Shin, ${ }^{\ddagger}$ Byungjoo Kim, ${ }^{\ddagger}$ Russell L. Jarek, ${ }^{\ddagger}$ and Seung-Jin Han ${ }^{\ddagger}$ \\ FT-ICR Laboratory Department of Chemistry, Pohang Lniversity of Science and Technology, \\ San3I Hoja-dong Namgu, Pohang 790-784, Korea \\ Division of Chemistry and Radiation, Korea Research Institute of Standards and \\ Science, P.O. Box 102, Yusong, Taejon 305-600, Korea

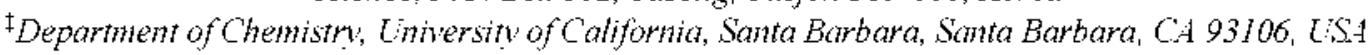 \\ Received Januarv 14, 2002
}

\begin{abstract}
Photodissociations of $o-m$ - and $p$-iodotoluene radical cations were investigated by using Fourier-transform ion cyclotron resonance (FT-ICR) spectrometry. Iodotoluene radical cations were prepared in an ICR cell by a photoionization charge-transfer method. The time-resolved one-photon dissociation spectra were obtained at $532 \mathrm{~nm}$ and the identities of $\mathrm{C}_{7} \mathrm{H}_{-}^{-}$products were determined by examining their bimolecular reactivities toward toluene- $d_{8}$. The two-photon dissociation spectra were also recorded in the wavelength range $615-670$ $\mathrm{nm}$. The laser power dependence, the temporal variation, and the identities of $\mathrm{C}_{:} \mathrm{H}_{-}^{-}$were examined at $640 \mathrm{~nm}$. The mechanism of unimolecular dissociation of iodotoluene radical cations is elucidated: the lowest barrier rearrangement channel leads exclusively to the formation of the benzyl cation whereas the direct C-I cleavage channel yields the tolyl cations that rearrange to both benzyl and tropylium cations with dissimilar branching ratios among $o-m$-. and $p$-isomers. With a two-photon energy of $3.87 \mathrm{eV}$ at $640 \mathrm{~mm}$. the direct $\mathrm{C}$-I cleavage channel results in the product branching ratio. [tropỵlium cation]/[benzyll cation], in descending order. 0.16 for meta $>0.09$ for ortho $>0.05$ for para
\end{abstract}

Keywords : FT-ICR. Time-resolved photodissociation. Iodotoluene. Tolyl cation. Product-resolved photodissociation.

\section{Introduction}

Unimolecular dissociations of iodotoluene radical cations ${ }^{\text {l-1] }}$ have attracted nuch experimental interest for the elucidation of the mechanism of $\mathrm{C}_{7} \mathrm{H}_{7}^{-}$formation. ${ }^{1-14}$ Iodotoluene radical cations with a few eV internal energies dissociate to $\mathrm{C}_{7} \mathrm{H}_{7}^{-}$with a loss of iodine. A number of studies have focused on the dissociation kinetics ${ }^{1-5}$ as well as the structures ${ }^{1.6-9}$ of $\mathrm{C}_{7} \mathrm{H}_{7}^{+}$from electron inpact (EI) or chemical ionization of iodotoluenes. The two-channel picture currently accepted for these dissociations is as follows: The direct C-I bond cleavage. denoted channel I, produces tolyl cations. ${ }^{3}$ whereas the lowest barrier rearrangement denoted channel II. yields the benzyl cation. ${ }^{14}$ Thermochemical thresholds for channel I. estimated from the recommended values for heats of formation of tolyl cations. ${ }^{15}$ are 2.11 . 2.24 , and $2.41 \mathrm{eV}$ for $o-, m$ - and $p$-iodotoluene radical cations. respectively. The activation barriers for channel II are determined to be $1.77,1.88$, and $1.90 \mathrm{eV}$ for $o-m-$ and $p$-isomers. respectively. ${ }^{16}$

In spite of a wealth of information about the kinetics and energetics of the system, the propensity of isomerization of tolyl cations to the benzyl cation and/or to the tropylium cation has not been well established. All the previous structural studies did not separate partial contributions from each channel. ${ }^{16-9}$ In this work. we have differentiated the two competing dissociation channels by energy-selective excitation

${ }^{\text {\$This paper is dedicated to K.H. Jung on the occasion of his retire- }}$ ment. of the iodotoluene radical cations and studied the structures of $\mathrm{C}_{7} \mathrm{H}_{7}^{+}$by ion-molecule reactions with toluene- $d_{8}$. The one-photon dissociation (IPD) at $532 \mathrm{~nm}$ leads to chamel II only for both $m$ - and $p$-isomers. whereas the two-photon dissociation (2PD) at $640 \mathrm{~nm}$ selects channel I predominantly for the $o$-isomer. The propensity of isomerization of tolyl cations were assessed by comparing the product branching ratios, [tropylium cation]/[benzyl cation], obtained from this work with the channel branching ratios. [channel I]/[channel II]. reported elsewhere. ${ }^{\text {li }}$

\section{Experimental Section}

Our FT-ICR setup for the studies of time-resolved photodissociation (TRPD) spectroscopy and bimolecular reactivity was previously described in detail. ${ }^{13.14}$

In brief the iodotoluene radical cations were prepared in the ICR cell by a photoionization-charge-transfer (PICT) method. ${ }^{13}$ First. $\mathrm{C}_{6} \mathrm{D}_{5} \mathrm{CD}_{3}{ }^{+}$was produced from two-photon ionization (2PI) of toluene- $d_{s}$ by the 266-1m output of a $\mathrm{Nd}$ :YAG laser. A 3-1mm diameter laser bean was used unfocused with a laser power of $\sim 2 \mathrm{~mJ} /$ pulse. Because the ionization potential (IP) of toluene. $8.83 \mathrm{eV}^{17}$ is greater than the IPs of iodotoluenes. 8.58, 8.56, and $8.43 \mathrm{eV}$ for $a-m-$, and $p$-isomers. ${ }^{1}$ respectively. exothermic charge-transfer (CT) reactions of $\mathrm{C}_{6} \mathrm{D}_{5} \mathrm{CD}_{3}{ }^{+}$with iodotoluenes yielded iodotoluene radical cations. The parent ions then underwent both radiative relaxation and thermal charge-exchange collisions with parent neutrals for $2 \mathrm{~s}$ before photolysis. Thus, the PICT process rapidly prepares thermalized parent ions at the 
housing temperature $\left(20^{\circ} \mathrm{C}\right){ }^{13}$ The parent ions were then optically excited by the 532-nm output of another Nd:YAG laser or by a tunable dye laser with the output in the wavelength range of 615-675 $\mathrm{km}$ with DCM dye pumped by the $\mathrm{Nd}$ :YAG laser. The photolysis laser beam was $2 \mathrm{~mm}$ in diameter and the laser power was $1-3 \mathrm{~mJ} /$ pulse for $1 P D$ at $532 \mathrm{~nm}$ and $-10 \mathrm{~mJ} /$ pulse for nultiphoton dissociations in the 615-670 nu wavelength range. The rapid internal conversion transformed the deposited photon energy into the internal energy, which resulted in vibrationally hot ions. The temporal appearance of $\mathrm{C}_{7} \mathrm{H}_{7}{ }^{+}$was monitored by scanning a $20-\mu$ S ICR detection burst on resonance with the ICR frequency of $\mathrm{C}_{7} \mathrm{H}_{7}^{-}$. The precise timing of photolysis pulse with respect to the ICR detection pulse was monitored by a fast photodiode. The structures of $\mathrm{C}_{7} \mathrm{H}_{7}{ }^{-}$from IPD at 532 $\mathrm{nn}$ and $2 \mathrm{PD}$ at $640 \mathrm{~nm}$ were identified from their binolecular reactivities toward toluene- $d s$. A 20 -s reaction time was allowed after photolysis to ensure the completion of ion-molecule reactions.

All chemicals were purchased from Aldrich Inc. and used after several freeze-pump-thaw cycles. The background pressure was below $9.0 \times 10^{-11}$ torr. Gaseous iodotoluene and toluene- $d_{8}$ were guided separately into the ICR cell and their partial pressures were kept at a constant ratio of $2: 1$ in the $10^{-8}$ torr range, respectively.

\section{Results and Discussion}

One-photon dissociation at $\mathbf{5 3 2} \mathbf{~ n m}$. Photodissociations of $o-m$, and $p$-iodotoluene radical cations were examined at 532 un. Figure 1 shows the TRPD spectra. All three isomers show non-zero intercepts at $t=0$. The intercept increases with the laser power, indicating that the product ion signals within the first $20 \mu$ s result fron multi-photon processes. Thus, the laser power was adjusted in such a way to make the IPD dominant. The TRPD signals were analyzed by using the ICR signal equation convoluted with a truncated Boltzmann distribution for the internal energy of the parent ion. ${ }^{13}$ The average rate constant was derived

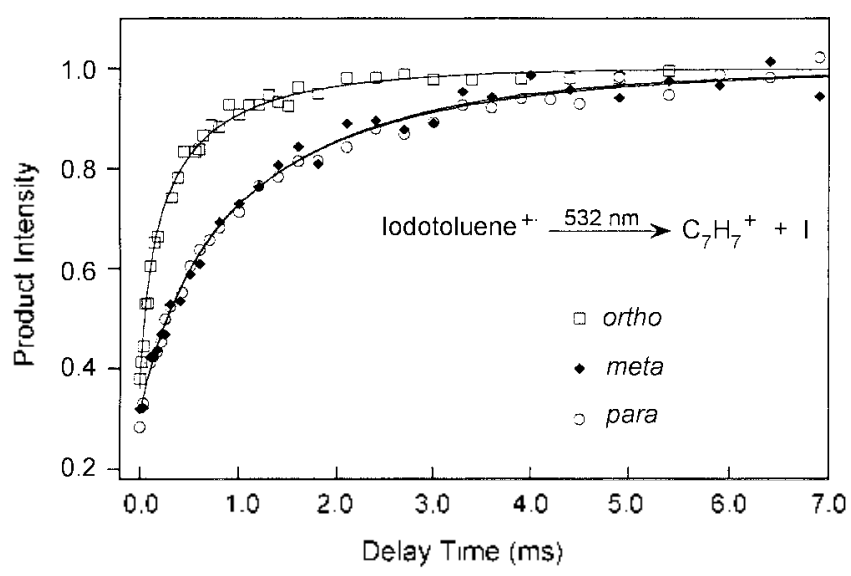

Figure 1. TRPD spectra of iodotoluene radical cations at $532 \mathrm{~nm}$. The solid lines represent the best-fit curves to the convoluted ICR signal equation.
Table 1. The dissociation rate constants of the $p$-iodotoluene radical cation as a function of time delay from EI

\begin{tabular}{cccc}
\hline time delay $(\mathrm{s})$ & $\mathrm{E}_{\text {thermal }}(\mathrm{eV})$ & Temperature & $k\left(\mathrm{~s}^{-1}\right)$ \\
\hline 0.05 & $0.33 \pm 0.03$ & $480 \pm 20$ & $3.2 \times 10^{4}$ \\
0.5 & $0.30 \pm 0.01$ & $460 \pm 10$ & $2.2 \times 10^{4}$ \\
1.0 & $0.27 \pm 0.01$ & $440 \pm 10$ & $1.5 \times 10^{4}$ \\
3.0 & $0.25 \pm 0.01$ & $425 \pm 10$ & $1.2 \times 10^{4}$ \\
\hline
\end{tabular}

therefrom. The solid lines drawn in Figure 1 represent the best-fit curves using the convoluted ICR signal equation. The average rate constants for IPD at $532 \mathrm{~cm}$ at $293 \mathrm{~K}$ are $4.300 \pm 300.890 \pm 60$, and $850 \pm 100 \mathrm{~s}^{-1}$ for $0-m$ - and $p$ iodotoluene radical cations, respectively. They are comparable to the previously reported values of $7.356 .1,775$, and 1.150 $\mathrm{s}^{-1}$ for $0-m-$, and $p$-isomers at $375 \mathrm{~K}$. respectively. by Dunbar and co-workers. ${ }^{5 \cdot 3}$ The two independent measurements show the descending order of rate in going from ortho to para. however. there is discrepancy in the order of magnitude. Our values are smaller than the previous experiments. We ascribe the discrepancy to the difference in ion temperature between the two experiments. To test the effect of electron impact (EI) on the ion temperature. we carried out TRPD themometry experiments with the $p$-isomer. The ion temperature was determined from the rate-energy curve as a function of time delay from a $16-\mathrm{eV}$ electron beam pulse. Results are summarized in Table 1. The IPD rate decreases with time and reaches a steady state. This result confirms that EI produces vibrationally hot ions that undergo radiative relaxation. but the radiative heating by hot filament keeps the ion temperature modestly ligh. ${ }^{13}$ The ion temperature was $\rightarrow 425 \mathrm{~K}$, even after $3 \mathrm{~s}$ delay from $\mathrm{EI}$.

Photodissociation in the $615-670 \mathrm{~nm}$ wavelength range The PD yield spectra were obtained in the 615-670 wavelength range and plotted in Figure 2. Both $o$ - and $p$ isomers exhibit almost identical appearance thresholds at $-670 \mathrm{~nm}$, while the $m$-isomer shows a significant PD signal at $670 \mathrm{~nm}$. These thresholds imply that there are optically bright excited states accessible by one-photon around 1.85 $\mathrm{eV}$ for all three isomers. The present spectra are in good agreement with the PD spectra reported by Dunbar and coworkers with photodissociation onsets of $1.8 \mathrm{eV}$ for all three

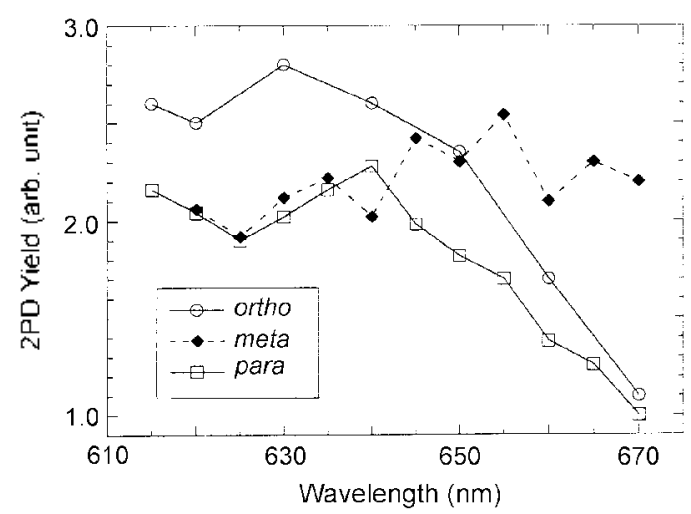

Figure 2. Two-photon yield spectra of iodotoluene radical cations. 

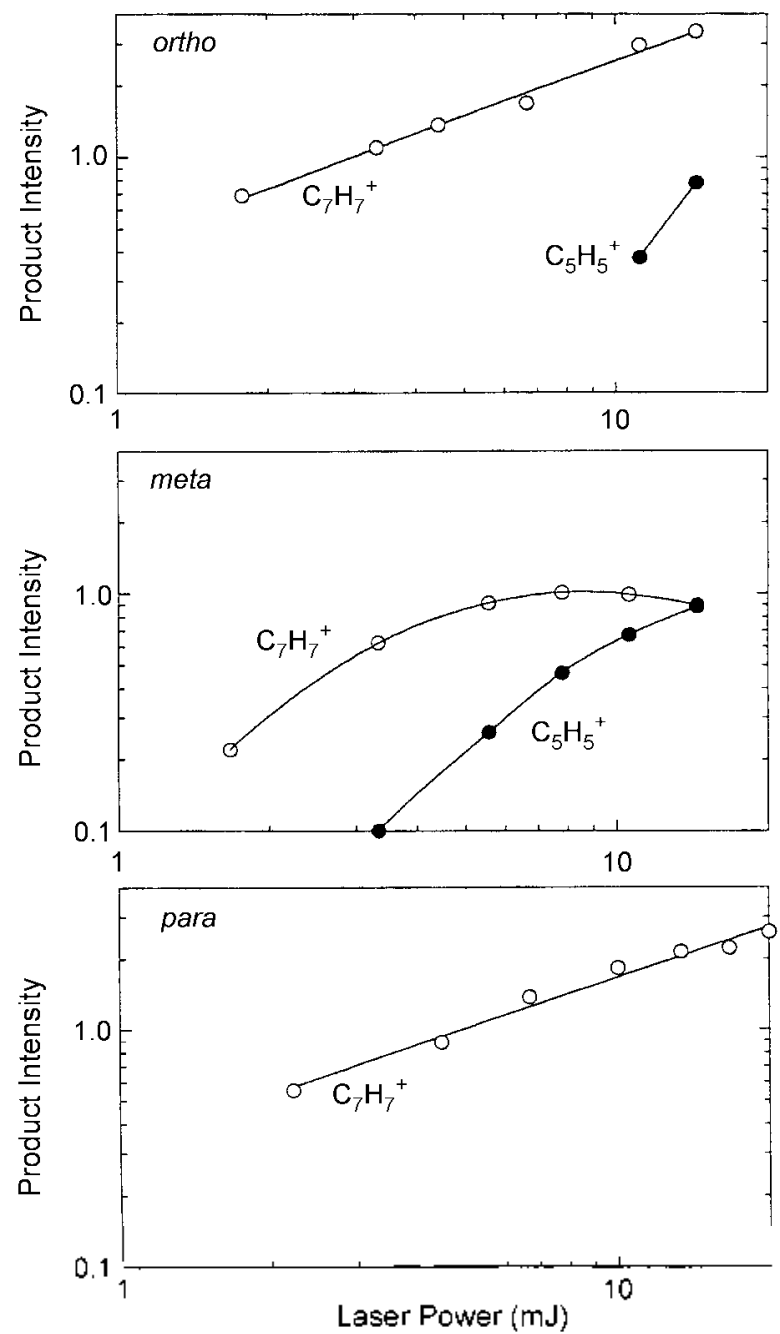

Figure 3. The laser power dependence of photodissociations of iodotoluene radical cations at $640 \mathrm{~mm}$.

isomers. $^{1+15}$ The laser power dependence was examined at $640 \mathrm{~lm}$, where all three isomers display comparable PD yields as shown in Figure 2. Results are shown in Figure 3. All three isomers reveal almost identical slopes of $0.7-0.8$ for the total product ion intensity as a function of laser power. These slopes suggest the saturation of one-photon absorption. As the laser power increases. $\mathrm{C}_{\Sigma} \mathrm{H}_{\Sigma}^{+}$appears in addition to $\mathrm{C}_{7} \mathrm{H}_{7}{ }^{+}$. however. their yields vary with isomers: $\mathrm{C}_{5} \mathrm{H}_{5}^{-}$starts appearing from the $\%$. and $m$-isomers at $\sim 11$ and $-3 \mathrm{~mJ} /$ pulse. respectively. but no $\mathrm{C}_{\Sigma} \mathrm{H}_{5}^{-}$appears from the $p$-isomer even at $20 \mathrm{~mJ} /$ pulse. The temporal appearance of $\mathrm{C}_{7} \mathrm{H}_{7}^{+}$was examined at $640 \mathrm{~nm}$ with low laser power. Figure 4 shows the appearance curve from the $p$-isomer. All $\mathrm{C}_{7} \mathrm{H}_{7}^{-}$products appeared within the first $20 \mu$ s. suggesting the $\mathrm{PD}$ rate greater than $-10^{5} \mathrm{~s}^{-1}$. Other isomers exhibited almost identical appearance curves as that of the $p$-isomer. Because one-photon energy of $1.94 \mathrm{eV}$ at $640 \mathrm{~lm}$ is just above the channel II activation barrier of $1.90 \mathrm{eV}$ for the $p$ isomer, the IPD rate is expected to be much less than $100 \mathrm{~s}^{-}$. On the other hand, the 2PD rate with a $3.87-\mathrm{eV}$ internal energy is expected to be in the range of $10^{6}-10^{7} \mathrm{~s}^{-1}$ for the $p$ -

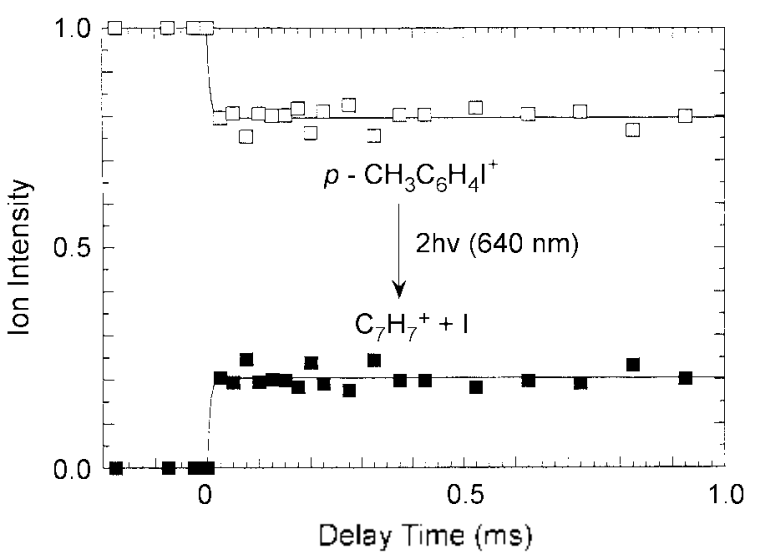

Figure 4. TRPD spectra of the $p$-iodotoluene radical cation at 640 nm.

isomer. Thus, the $\mathrm{C}_{7} \mathrm{H}_{7}^{+}$signal within the first $20 \mu \mathrm{s}$ must result from at least two-photon process. The subsequent $\mathrm{C}_{5} \mathrm{H}_{5}{ }^{-}$signal at ligh laser power is presumably derived from the sequential dissociation of the iodotoluene radical cations wa $\mathrm{C}_{7} \mathrm{H}_{7}^{+}$. If $\mathrm{C}_{5} \mathrm{H}_{5}^{-}$were the vinylcyclopropenyl cation as suggested by Freiser et $a .{ }^{18}$ thermochemical thresholds to give $\mathrm{C}_{5} \mathrm{H}_{5}{ }^{+}+\mathrm{C}_{2} \mathrm{H}_{2}+\mathrm{I}$ would be 3.65 .3 .81 . and $3.78 \mathrm{eV}$ for the $o-, m$ - and $p$-iodotoluene radical cations. respectively. Because the two-photon energy of $3.87 \mathrm{eV}$ at $640 \mathrm{num}$ barely meets these thresholds, the formation of $\mathrm{C}_{5} \mathrm{H}_{5}^{-}$by twophoton absorption does not kinetically compete with that of $\mathrm{C}_{7} \mathrm{H}_{7}^{-}$having the rate of $10^{6} \cdot 10^{7} \mathrm{~s}^{-1}$. To produce an appreciable amount of $\mathrm{C}_{5} \mathrm{H}_{5}^{-}$as shomn in Figure 3 at ligh laser power, at least three photon processes should take place. Therefore, we conclude that the $\mathrm{C}_{5} \mathrm{H}_{5}{ }^{-}$signal is indicative of three-photon process. while the $\mathrm{C}_{7} \mathrm{H}_{7}{ }_{7}^{-}$signal in the absence of $\mathrm{C}_{5} \mathrm{H}_{5}{ }^{-}$results mainly from two-photon process. The difference in the laser power dependence of product spectra among three isomers may be related to the difference in the rate of internal conversion that affects the overall rate of two-photon absorption.

Structures of $\mathrm{C}_{7} \mathrm{H}_{7}^{+}$products. In 532-1nm photoly sis, the $\mathrm{C}_{7} \mathrm{H}_{7}^{-}$products formed within the first $20 \mu$ s were ejected out by applying an ejection radio-frequency pulse at $20 \mu \mathrm{s}$ after photolysis. because they were derived from at least two-photon process. The rest of $\mathrm{C}_{7} \mathrm{H}_{7}$ solely from IPD was tested for their chemical reactivities toward toluene- $d /$. In 640-nm photoly sis. the laser power was adjusted to increase the $2 \mathrm{PD}$ signal of $\mathrm{C}_{7} \mathrm{H}_{7}^{-}$while suppressing the 3PD signal of $\mathrm{C}_{5} \mathrm{H}_{5}^{-}$below the detection limit, and all $\mathrm{C}_{7} \mathrm{H}_{7}^{+}$products were analyzed. It has been well known that the benzyl cation undergoes reactions $1-3$ with toluene- $d_{8}$. whereas the tropylium cation remains unreactive. ${ }^{14.19}$

$$
\begin{aligned}
& \mathrm{C}_{7} \mathrm{H}_{7}^{-}+\mathrm{C}_{6} \mathrm{D}_{5} \mathrm{CD}_{3} \longrightarrow \mathrm{CD}_{3} \mathrm{C}_{6} \mathrm{D}_{4} \mathrm{CH}_{2}^{+}+\mathrm{C}_{6} \mathrm{H}_{5} \mathrm{D} \\
& \mathrm{C}_{7} \mathrm{H}_{7}^{-}+\mathrm{C}_{6} \mathrm{D}_{5} \mathrm{CD}_{3} \longrightarrow \mathrm{C}_{6} \mathrm{D}_{5} \mathrm{CD}_{2}^{-}+\mathrm{C}_{7} \mathrm{H}_{7} \mathrm{D} \\
& \mathrm{C}_{6} \mathrm{D}_{5} \mathrm{CD}_{2}^{-}+\mathrm{C}_{6} \mathrm{D}_{5} \mathrm{CD}_{3} \longrightarrow \mathrm{CD}_{3} \mathrm{C}_{6} \mathrm{D}_{4} \mathrm{CD}_{2}^{+}+\mathrm{C}_{6} \mathrm{D}_{6}
\end{aligned}
$$

Table 2 summarizes the product branching ratio, [tropylium cation]/[benzyl cation]. obtained from this work and the chamel branching ratio. [channel I]/[channel II], for IPD at 
Table 2. The channel branching ratios, [channel I]/[chamel II], and the product branching ratios, [tropylium $\left.{ }^{+}\right] /\left[\right.$benzy $1^{+}$], of iodotoluene radical cations

\begin{tabular}{|c|c|c|c|c|}
\hline & \multicolumn{2}{|c|}{$1 P D$ at $532 \mathrm{~nm}$} & \multicolumn{2}{|c|}{ 2PD at $640 \mathrm{~mm}$} \\
\hline & $\overline{\left[\operatorname{ch~I]} /[\operatorname{ch~II}]^{a}\right.}$ & {$\left[\mathrm{tr}^{-}\right] /\left[\mathrm{bz}^{-}\right]$} & $\overline{[\operatorname{ch~I}] /[\operatorname{ch~II}]}$ & $\left.\mathrm{tr}^{+}\right] /\left[\mathrm{bz}^{+}\right]$ \\
\hline$o$-iodotoluene & $55 / 45$ & $4 / 96$ & $98 / 2$ & $8 / 92$ \\
\hline$m$-iodotoluene & $0 / 100$ & $0 / 100$ & $94 / 6$ & $13 / 87$ \\
\hline$p$-iodotoluene & $0 / 100$ & $0 / 100$ & $77 / 23$ & $4 / 96$ \\
\hline
\end{tabular}

"Reference 16.

$532 \mathrm{~nm}$ and $2 \mathrm{PD}$ at $640 \mathrm{~nm}$ estimated from the RRKM rateenergy curves. ${ }^{3,16}$ When channel II was selected by photolyzing $m$ - and $p$-isoners at $532 \mathrm{~nm}$, all $\mathrm{C}_{7} \mathrm{H}_{7}{ }^{+}$products reacted away. indicating the benzyl cation structure. When channel I was selected by photolyzing the $\sigma$-isomer with two photon at $640 \mathrm{~lm}$, a few percent of $\mathrm{C}_{7} \mathrm{H}_{7}^{-}$remained unreactive, indicating the presence of the tropyliun cation. These tropylium cations must be derived from the isomerization of tolyl cations produced from channel I. The product branching ratios obtained in this work are in qualitative agreement with those reported by Jackson et al. ${ }^{6}$ using EI in an ICR cell. Because the channel branching ratio is available as a function of internal energy, the isomerization branching ratio of the $0-m-p$-tolyl cations are derived. They are 0.089 .0 .16 . and 0.055 for $o-, m$ - and $p$-tolyl cations, respectively. Results are given in Table 3.

The present result with iodotoluene radical cations provides direct evidence that channel I leads to the tolyl cations that isomerize to both tropylium and benzyl cations, and confirms our previous conclusion with bromotoluene radical cations that channel II leads predominantly to the benzyl cation. However. the mechanism of isomerization is still elusive. Recent theoretical work at a B3LYP/6-3IG(d.p) leve ${ }^{\hat{i j}}$ presented activation barriers of $1.08 \mathrm{eV}$ for the $\mathrm{H}$ atom migration from the $o$-tolyl cation to benzyl, $1.17 \mathrm{eV}$ for the rearrangement of the o-tolyl cation to tropylium via benzyl, $1.96 \mathrm{eV}$ for the isomerization of the $m$-tolyl cation to ortho. and $2.05 \mathrm{eV}$ for the $\mathrm{H}$-atom migration in the phenyl cation. The $\mathrm{H}$-atom migration from the $p$-tolyl cation to meta is expected to have an activation barrier similar to that in the phenyl cation. Thus, if the $\mathrm{H}$-atom migration is the mechanism of isomerization of the tolyl cations to benzyl or tropylium. theoretical activation barriers to the benzyl cation are 1.08. 1.96, and $2.05 \mathrm{eV}$ for $o-m$. and $p$-tolyl cations. respectively, and those to the tropy lium cation are 1.17. 1.96. and $2.05 \mathrm{eV}$. respectively. In experiment, the $2 \mathrm{PD}$ at $640 \mathrm{~nm}$

Table 3. The isomerization branching ratios of the tolyl cations from channel I

\begin{tabular}{ccc}
\hline & \multicolumn{2}{c}{$\left[\right.$ tropylium $\left.\left.^{+}\right] /[\text {benzy }]^{-}\right]^{4}$} \\
\cline { 2 - 3 } & IPD at $532 \mathrm{~nm}$ & 2PD at $640 \mathrm{~nm}$ \\
\hline$o$-tolyl & 0.078 & 0.089 \\
$m$-tolyl & - & 0.16 \\
$p$-tolyl & - & 0.055 \\
\hline
\end{tabular}

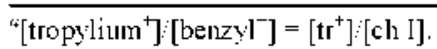

releases 1.76 .1 .63 , and $1.46 \mathrm{eV}$ excess energies in channel I for $0-m$. and $p$-iodotoluene radical cations. respectively. On the other hand. the IPD at $532 \mathrm{~nm}$ provides 0.22 and $0.09 \mathrm{eV}$ excess energies in channel I for $o$ - and $m$-iodotoluene radical cations, respectively. For para. the channel I threshold is greater than the one-photon energy at $532 \mathrm{~nm}$. When compared with theory, if the $\mathrm{H}$-atom migration is the only mechanism of isomerization of the tolyl cations, we should not have detected the tropylium cation from both IPD of the $o$-isomer at $532 \mathrm{~nm}$ and 2PD of $m$ - and $p$-isomers at $640 \mathrm{~nm}$. Moreover. the formation of the tolyl cation itself from channel I has been firmly established as evidenced by the ion-molecule reaction with dimethyl ether. ${ }^{21}$ Thus. to account for our results as well as others. the more elaborate mechanism than the $\mathrm{H}$-atom migration needs to be considered. Further theoretical investigations are called for.

\section{Conclusion}

In unimolecular dissociations of iodotoluene radical cations. the lowest barrier rearrangement channel II leads exclusively to the formation of the benzyl cation, whereas the direct C.I cleavage channel I yields the tolyl cations that isomerize to both benzyl and tropylium cations with dissimilar branching ratios among $o-m$ - and $p$-isomers. The isomerization of tolyl cations involves more than $\mathrm{H}$-atom migration in the mechanism.

Acknowledgment. S.K.S. acknowledges the partial support from the National Science Foundation Young Investigator Award (CHE-9457668) while at UCSB, the National Research Laboratory Program of Korea Institute of Science and Technology Evaluation and Planning. and the Brain Korea 21 Program.

\section{References}

1. Olesik. S.: Baer. T.: Morrow. T. C.: Ridal. J. T.: Buschek. T.: Holmes. J. L. Org Hass Spectrom. 1989, 24. 1008.

2. Dunbar. R. C.; Lifshitz. C. J. Chem. Plys. $1989,94,3542$

3. Lin. C. Y.: Dunbar. R. C.J. Phus. Chem 1994, 98.1369.

4. Choe. J. C.: Kim. M. S. Int J. Mass Spectron. Ion Processes 1991. 107. 103.

5. Cho. Y. S.: Kinn. M. S.: Choe. J. C. Int. J. Mass. Spectront Ion Processes 1995, 145. 187

6. Jackson. J.-A. A.: Lias, S. G.: Ausloos, P. J. Am. Chem. Soc. 1977. 99.7515 .

7. McLafferty. F. W. Winkler. T. J. An Chen. Soc. 1974. 96.5182.

8. McLafferty. F. W.: Bockhoft. F. M. J. Ant Chent. Soc. 1979. 101. 1783

9. Proctor. C. T.: McLafferty. F. W. Org Mass Spectrom. 1983. J8. 193.

10. Dunbar, R. C. Honovich. J. P.: Asamoto, B. J. Phys. Chem. 1988. 92.6935 .

11. Lifshitz, C.: Levin, I.; Kababia, S.; Dunbar. R. C. J. Plys. Chem. 1991.95. 1667

12. Lifshitz. C. Acc. Chent Res 1994. 27. 138

13. Shin. S. K.: Han. S-T.: Kimn. B. Int. J. Mass. Spectron. Ion Processes 1996, 158. 345

14. Kim, B.; Shin, S. K. J. Chem. Phws. 1997. 106, 1411.

15. Shin. S. K. Chem. Plys. Lett. 1997. 280. 260.

16. Kim. B.: Shitr. S. K.. unpublished.

17. Lu. K. T: Eiden. G. C.: Weisshaar. T. C. J. Phns Chem 1992.96.9742

18. McCrery. D. A.: Freiser. B. S. J. Am. Chent. Soc. 1978. 100.2902.

19. Shen. J; Dunbar, R. C.: Olah. G. A. J. Am. Chw Soc. 1974, 96.6227.

20. Ignatyev, I. S.; Sundius, T. Chem. Phys. Lett. 2000, 326. 101. 